ABRAHAM NOSNIK O.

\title{
Las personas de James y Mead*
}

\section{Antecedentes}

D ARA los lectores en nuestra lengua William James no es - un autor completamente desconocido. A James se le conoce como lilósofo y psicólogo. Es difícil precisar qué tanto. Sin (mbargo, por lo menos sabemos que James fue figura importante en el movimiento llamado Pragmatismo, única escuela de pensamiento en la historia de la filosofia originaria de ticmas americanas y cxportada para ser adoptada en diferentes ámbitos curopeos, sobre todo a Inglaterra, Italia y España. En csta última Abbagnano (1963) reconoce el espíritu pragmatista de Unamuno (Vida de don Quijote y Sancho y Del sentimienfo trágico de la trida) y en el propio Ortega y Gasset (El tema de mestro tiempo. En torno a Galileo e Historia como sistema, en otros). También sabemos que James fue uno de los personajes contrales en la consolidación de la psicología como materia cicntilica a lines del siglo XIX, en los Estados Unidos, y que sus Principles of Psychology (1890), en sus versiones amplia y hreve, ayudaron a formar las primeras generaciones de profesionales americanos en esta materia. Un segundo mérito de Jances en materia de psicologia fue haber establecido el primer laboratorio experimental en Estados Unidos - on la Uni-

* El autor quiere hacer público su agradecimiento y reconocimiento al protesor Richard Pruitt del Departamento de Filosofia de la Universidad de Stanford, por su apoyo y entusiasmo a la idea del análisis que aquí se presenta. Esta es una versión modificada de su original en inglés presentado en la. Universidad de Stanford en Marzo de 1982. 
versidad de Harvard-, al regreso de una gira por Europa donde tuvo la oportunidad de visitar el laboratorio del Dr. Wundt, en Alemania. Por último, James también es conocido por haber sido hermano del novelista Henry James. Algunos enterados que conocen a fondo el trabajo de los hermanos dicen, no completamente en broma, que William era poseedor de un estilo que hacía de sus estudios verdaderas piezas "noveladas" de la materia que trataban y que Henry, por el otro lado, mostraba en sus novelas una agudeza y una profundidad de un psicólogo profesional.

George Herbert Mead, en cambio, es una figura poco conocida no sólo en nuestras latitudes sino incluso en Estados Unidos. Americano y filósofo como James, su mayor influencia se ha dado en las áreas de sociologíà, psicología social y estudios sobre lenguaje.

En sociología se le considera uno de los padres fundadores, junto con John Dewey y Charles $\mathrm{H}$. Cooley, del Interaccionismo simbólico, término acuñado por Herbert Blumer -alumno de Mead-que nombra a una de ls escuelas de pensamiento más influyentes en el estudio de la relación individuo y sociedad. El Interaccionismo simbólico es aún una tradición que participa en los debates teórico-metodológicos en ciencias sociales a través de su impulso a las llamadas metodologías "cualitativas" (v. gr., etnometodología); también debemos mencionar el reconocimiento de figuras importantes en diversos campos (Habermas en Hermenéutica, Moscovici en Psicología Social y Bruner' en el estudio del lenguaje), prueba de la importancia y vigencia de las ideas de Mead.

Mead fue íntimo amigo y colega de John Dewey: quien, junto con Charles S. Pierce y el propio William James, es una de las tres figuras más grandes que diera el Pragmatismo. Cuando William Rainey Harper fundó la Universidad de Chicago, al final del siglo pasado, invitó al entonces joven filósofo Dewey de la Universidad de Michigan a dirigir el departamento de filosofia. Dewey aceptó bajo una condición: traer con él a George Herbert Mead. Bajo el liderazgo de Dewey, el departamento de Filosofía de la Universidad de Cinicago llegć

1 Jerome Blumer ocupa, de hecho; una cátedra en la New School for Social Rescarch en memoria de Mead: George Herbert Mead University Professor. 
a ser uno de los centros de investigación y docencia con orientación pragmatista más distinguidos en los Estados Unidos. Entre las figuras más preclaras de ese departamento estaba Mead, quien, junto con Dewey y James Hayden Tufts, consolidó las bases filosóficas y teóricas de la que sería después -y hasta ahora- una de las escuelas que más ha contribuido al estudio de "lo social". Dewey dejó en 1894 Chicago para ir a Columbia. Mead se quedó en Chicago hasta el día de su muerte en 1931 , a la edad de setenta y ocho años.

\section{Comentario introductorio}

En este artículo hablaremos de un término difícil de definir de una manera clara y precisa: el "Self". En castellano no existe un equivalente que refleje exactamente la riqueza de este concepto. Algunos autores han optado por conservar intacto el término y asi hablan del "Self" ". Otros han recurrido a "persona" (como en el título en castellano del libro de Mead Espíritu, persona y sociedad, dél original en inglés Mind, Self and society). Una tercera estrategia incluye el concepto "yo". Sin embargo, en el caso concreto de las teorias de James y Mead sobre el "Self' el concepto que mejor equivale, según mi opinión, a la riqueza de referentes del término es precisamente persona. Como se verá más adelante, lo que James y Mead nos tratan de descubrir con sus teorías es cómó el ser humano, cada miembro individual de nuestra especie, surge psicológica (con James) y socialmente (con Mead) como persona.

Dado todo lo anterior, he optado por un plan que dista mucho de ser una decisión salomónica, pero que refleja mis intenciones al escribir este artículo. Por un lado, he incluido en el título de esta exposición la palabra "persona" que, como ya lo dije, es para mí la mejor traducción de "Self' a nuestro idioma. Por el otro lado, he conservado en el texto el concepto "Self" en inglés, con el objetivo de dar a conoer los tratamientos de James y Mead de este término en su sentido más original. Después de leer la presente exposición, el lector estará en mejor posición para decidir qué término le viene bien al "Self" de estos dos americanos. 
El "Sell" es un concepto importante. Evidencia de ello es el rol central que ha tenido tanto en filosofia como en las ciencias sociales y de la conducta: psicologia (James, 1890), sociología (Cooley, 1902; Blumer, 1938), educación (Dewey, 1922) y psicología social (Mead, 1934; Newcomb, 1950).

El objetivo de este artículo es presentar las teorías del "Sell" de James y Mead, compararlas y ubicarlas dentro de la geogralia intelectual del Pragmatismo.

Las primeras dos secciones exponen, espero, de una manera representativa, las ideas centrales de estos dos autores con respecto al "Self'. La tercera sección fue escrita teniendo en cucnta que su mayor contribución debe ser el contraste entre los enfoques de James y Mead. La última parte del texto busca un marco de referencia común donde podamos ubicar ambas teorías. Esta sección de ninguna manera busca ser reconciliadora (no tendría caso) sino pretende situar el trabajo de los autores en su contexto norteamericano original.

\section{La "Conciencia del Self" de William James"}

Uno de los logros más citados del tratamiento de James de la noción de "Self" en sus Principles of Psichology (1890) es haber dado una descripción no metafísica de este concepto.

Fue precisamente el capítulo de James sobre el "Self" lo que brindó nuevas oportunidades para teorizar, especular y, eventualmente, experimentar en diferentes áreas del quehacer científico referido a la naturaleza y acción humanas.

El capítulo sobre la "Conciencia del Self" está dividido en tres partes.

1.- El Ego empírico: En esta parte el autor hace una descripción física, psicológica y social del "Self". Es precisamente en esta parte, en mi opinión, donde el análisis de James es más novedoso y fresco. Es aquí donde el autor explica la naturaleza 'polifacética' e 'inclusiva' del "Self". Es aquí donde menciona la fundación social del ser humano. Y es aquí donde James incorpora en una sola explicación los aspectos afec-

2 Las referencias y citas a capítulos, libros y textos tanto en esta sección como culas siguientes són a los originales en inglés. 
tivos (v. gr., autoestima) e instintivos (v. gr., autopreservación) de los humanos.

2.- El Ego Puro: los temas incluidos en esta sección son dos: identidad personal y el 'Self' puro o la unidad personal. Es imporante el tratamiento que hace el autor del "Self" puro donde menciona los tres puntos de vista famosos históricamente al respecto: la teoría Espiritualista, la teoría Asociacionista y la teoría Trascendentalista.

Es interesante notar que James critica la noción trascendental del "Self" (Ego Puro) al referir sus propias descripciones (empírica y psicológica) del "Self".

3.- Las mutaciones del "Self": En esta tercera y última parte del capítulo, James hace una larga descripción de los aspectos psicopatológicos y cambiantes del "Self'. Aquí James incluye varias historias detalladas acerca de "experiencias raras" que le pasan a la gente. Esta sección cierra el exhaustivo análisis -tanto científico como metafísico- de la naturaleza del "Self".

Dada la panorámica general del capítulo sobre la "Conciencia del 'Self", veamos ahora de manera detallada su contenido.

1.- El Ego Empírico: Según James, el "Self" empírico es "todo lo que él (el individuo) está tentado a llamar 'mi" " (p. 291). Nuestro autor dice que es muy difícil distinguir entre lo que llamamos "mi" y lo que referimos como "mio". "Sentimos y actuamos con respecto a cosas que son nuestras", afirma, "en mucho como sentimos y actuamos con relación a nosotros mismos"' (p. 291).

Las características arriba descritas delinean el sentido "inclusivo del 'Self'.". James incluye en este uso del "Self" todo aquello que es nuestro, todo lo que forma parte de nosotros: cosas, objetos y gente que es parte de nuestra expe-riencia. Es precisamente el hecho de que todo esto (v. gr., nuestra fama, nuestros hijos, el trabajo realizado con nuestras

3 Aqui menciono como importante la oposición de James a la noción kantiana con su "Self", porque al hacerlo James contrasta la deseripción trascendentalista con su psicología del "Self" incorporando un nuevo ámbito en el debate sobre la naturaleza humana e ilustrandọ, con esta instancia, su método pragmatista de análisis. 
manos) es constitutivo de nuestra experiencia que lo hace parte de nosotros.

Quizá suenc tautológico pero si reflexionamos en lo que açabamos de señalar no lo encontraremos así. Lo importante que James está haciendo aqui, me parece, es llamar nuestra atcrión al hecho de que el "Self" es la suma (por carencia de una mejor palabra) del individuo y su experiencia. Experiencia, a c'stas alturas, no puede ser entendida como una entidad metalísica sino un constructo psicológico, esto es lo novedoso en la descripción de James".

Este primer significado de lo inclusivo del "Self"' (v. gr., no sólo lo que es "mi", sino también lo que es "mio") da pie al segundo sentido de esta noción. Se trata de su naturaleza polifacética. James nos explica que un individuo es un conjunto de "Selves"5 sociales y que éstos son tan numerosos como la cantidad de personas que reconocen al individuo y llcyan en sus mentes su imagen. Ofender a este individuo en cualquiera de estas sus imágenes, nos dice James, es ofenderlo.

En mi opinión, James nos ofrece el aspecto psicológico del "Scll" cuando nos habla de su naturaleza inclusiva e incorpora el orden social en su análisis cuando incluye el aspecto polifacético de la noción. Esto es importante por cuando menos dos razones. La primera, he sido especialmente cuidadoso en presentar lo inclusivo y lo polifacético del "Self" por separado porque, desde mi punto de vista, la concepción de James del "Self" es primariamente "psicológica". A pesar de que en la descripción que nos ocupa lo psicológico y lo sociológico son aspectos difíciles de separar, James los mantiene separados. Es sólo posteriormente, y he aquí la segunda razón, con los trabajos de Cooley (1902) y Mead (1934) que el aspecto sociológico adquiere mayor peso en el análisis del "Sell". Más aún, con Cooley el "Self" es primordialmente una noción sociológica pues es el "Self" uno de los conceptos más básicos que da a'la sociedad su naturaleza orgánica, y es sólo con Mead que empezamos a hablar del "Self" como de

- Tomando en cuenta la distinción antes establecida entre el Ego empírico y d) Ego idcal o puro.

${ }^{5}$ Uso la lorma plural de "Self" en inglés, aquí y en futuras ocasiones. 
una noción psicosocial y la importancia de mantener esta doble dimensión (v. gr., psicológica y social) del término.

En este punto, me parece relevante introducir la muy conocida (véase Newcomb, 1950; Meltzer, Petras y Reynolds, 1975) clasificación de James del "Self"6. Esta es:
a. El "Sell"' material
b. El "Self" social
c. El "Self" espiritual
d. El Ėgo Puro.

a.- El 'Self' material. El cuerpo es la parte central del "Self" material. A pesar de que existe también en nosotros la tendencia a sentir "todo nuestro cuerpo"; también experimentamos algunas partes de él, dice Jamẹs, como más "intimamente nuestras" que el resto. Aquí se me ocurre preguntar si nuestro autor se refiere al hecho de que sobrevaloramos la importancia de nuestra cabeza y corazón por considerarlos tradicionalmente el locus de dos aspectos vitales nuestros, -inteligencia y afecto- respectivamente. Creo que si éste es el caso, James está acertado en lo que afirma.

En seguida, y todavía como parte del "Self' material, vienen nuestros vestidos, nuestra ropa. James nos dice que el viejo refrán "el hombre es su alma, cuerpo y vestido" es más que una broma. A continuación, nuestra familia más inmediata (a veces llamada nuclear), nuestro hogar y nuestras pericnencias. Todo esto con objeto de preferencias instintivas. Esto es, nos relacionamos con ello a través de impulsos ("impulsive drives") que son características básicas de nuestra naturaleza. Mi amigo y colega Javier Elguea gusta de mencionar nuestro "impulso básico sedentario" tan humano, caracterizado por nuestro coleccionar y almacenar tarjetas, cartas, papeles, libros, objetos, etc., en lugares donde hemos de permanecer viviendo temporalmente. A pesar de que sabemos que tenemos que trasladar todas nustras cosas de un lugar a otro.

"Algumos aspectos de lo que será presentado en seguida a veces redundan con los argunentos presentados hasta ahora. Sin embargo, me parece importante incluir la prescrnte clasificación con todas sus categorías pues ayudaría al lector a obtener una idca más clara y coherente del trabajo de James. 
b.-El "Self" Social. Como lo mencionamos anteriormente, el aspecto social del "Self" está dado por el hecho de que somos "alguien" para nuestros compañeros. James subraya nuestra necesidad de ser notados por los demás. Nos dice que "somos" no solamente animales gregarios, que gustamos de estar a la vista de nuestros congéneres, sino tenemos una propensión innata a hacernos notar y notar favorablemente, por los nuestros (p. 293). Según el autor, no podría haber peor castigo para el humano que ser abandonado por los demás y pasar absolutamente inadvertido por los miembros de su sociedad.

La segunda característica más importante del "Self" social, dice James, es su naturaleza polifacética. Este hecho se refiere a que el individuo tiene tantos "Selves" como gente que lo reconozca. Prima face esto suena un poco ingenuc. ¿Es posible para una persona tener tantas "caras" como gente que la reconoce? ¿ No existe un común denominador básico de características personales ${ }^{7}$ que identifican a un individuo a pesar de las situaciones en las que está y de las personas con las que entra en contacto?

Reconociendo los problemas que su explicación puede provocar, James agrega que el individuo tiene tantos "Selves" sociales como grupos distintos de personas existen cuya opinión toma en cuenta. A James le importa poco ofrecer una solución al problema que surge cuando el individuo entra en interacción social (?es un individuo "partido" en varios "Selves"?). Lo que a él le interesa es enfatizar la imagen de "la división del individuo en varios 'Selves' " (p. 294).

En su descripción de la interacción social, es decir, del "Self" social en acción James suena muy semejante a cualquier teórico del rol hablando sobre acción social ${ }^{8}$. Menciona las metas de la persona y su fama y honor (p. 294) de una manera que en mucho se asemeja a la discusión de la prescripdel "Sell".

"Evito a propósito el término "personalidad" para no restringir la noción

${ }^{8}$ Bueno, esto no nos debe sorprender. La teoría del Rol evolucionó a partir y es un producto de los primeros teóricos del "Self" como James y Mead. Sin embargo, creo que es un aspecto que debe apuntarse. 
ción y descripción de roles, expectativa y status (véase Deutsch y Krauss, 1976). La noción de James de "la opinión de club" (p. 295) nos recuerda normas de grupo y conceptos como conformismo, atmósfera de grupo, realidad grupal, desviación y rechazo, etc. ${ }^{9}$

c.-El "Self" espiritual. El "Self" espiritual, según James, se refiere a su aspecto subjetivo, a las facultades o disposiciones psíquicas tomadas concretamente (en contraste con el principio de unidad personal, que él explica cuando habla del Ego Puro). Según nuestro autor, "estas disposiciones psíquicas son la parte más permanente e íntima del 'Self', aquélla que más verdaderamente somos" (p. 296). El "Self" espiritual o conciencia tiene una naturaleza reflexiva: la persona es sujeto de sus propias reflexiones, es decir, el "Self" espiritual es la habilidad del individuo de pensarse como un ser reflexivo, es el "Self" de todos los demás "Selves" (p. 297).

Después de una larga descripción de su propia experiencia, James reconoce que "... (al menos en algunas personas) la parte más íntima del 'Self que es aquélla sentida de manera más viva resulta ser en su mayoría una colección de movimientos cefálicos de 'ajuste' ${ }^{10}$, que por una necesidad de atención y reflexión, usualmente no pueden ser percibidos y clasificados como lo que son".

Y agrega: “...por sobre estos (movimientos de ajuste) existe un sentimiento más obscuro de algo más; sin embargo, si es que se trata de procesos fisiológicos más débiles o de nada (que pueda ser considerado) objetivo sino de la subjetividad como tal, de pensamiento convertido 'en su propio objeto', es algo que debe permanecer por ahora como una pregunta abierta..." (p. 305).

Finalmente, James incluye en su sección sobre el "Self"

9 DC ninguna manera estoy sugiriendo con esto que el estudio de la Dinámica dc Grupos (entre otros acercamientos al estudio de grupos) tiene su antecedente inmediato ('n James. Lo que aquí quiero decir es que la importancia del grupo en su inllucncia sobre la naruraleza y desarrollo del "Self" ya está presente en James.

10 Para James todos los actos fisiológicos se dividen en dos tipos: los "ajustes" y las "ejecuciones". El "Self" son los ajustes considerados colectivamente. La parte menos íntima, más cambiante del "Self", es decir, la parte activa, correspondería a las "ejecuciones". 
empírico las nociones de auto-estima (self-feeling) y autopreservación. La auto-estima se refiere a los aspectos afectivos del "Self" e incluye las dimensiones de auto-complacencia y auto-insatisfacción. Por otro lado, la auto-preservación corresponde a todos los impulsos instintivos fundamentales cuya meta es nuestra preservación física, social y espiritual.

d. - El Ego Puro. James divide esta parte de su capítulo en dos: la explicación del sentimiento de identidad personal y las tres teorías acerca del ego puro o ideal.

En la primera, el autor arguye que el sentido de identidad personal o la conciencia de la mismidad o similitud personal (personal sameness) puede ser tratada como un fenómeno subjetivo o una dinámica objetiva, un sentimiento, una verdad.

En la segunda sección del capítulo, James presenta tres teorías del Ego Puro o ideal. La Teoría Espiritualista o Teoría del Alma es "la teoría de la filosofia popular y la escolástica, que es solamente filosofia popular sistematizada. Declara que el principio de la individualidad dentro de nosotros debe ser sustancial, pues los fenómenos psíquicos son actividades y no puede haber ninguna actividad sin un agente concreto" (p. 143). La Teoría Asociacionista está, según James, basada en la hipótesis de Locke sobre el caso de una misma sustancia teniendo dos conciencias sucesivas, o que una misma conciencia está apoyada por más de una sustancia (pp. 350-351). Finalmente, la Teoría Trascendentalista, cuyo origen está en Kant, que empieza con la decripción de los objetos como sistemas de cosas, cualidades o hechos en relación. "El objeto, dice James parafraseando a Kant, es eso en el conocimiento (begriff) con lo cual lo humano (the Manifold) de una percepción está conectado" (p. 360). "La forma humana del objeto (Manifoldness of the object), James continúa, está dada por la sensibilidad que en sí misma es caótica y cuya unidad está dada por el manejo sintético que esta forma humana recibe de las facultades superiores de la Intuición, Aprehensión, Imaginación, Entendimiento y Apercepción. El material conectado debe estar dado por las facultades inferiores del Entendimiento, pues este último no es una facultad intuitiva, sino por naturaleza está 'vacío" " (p. 361). 


\section{La Teoria del 'Self" Social de George H. Mead}

Dé acuerdo con uno de los discípulos más brillantes de George Herbert Mead, Herbert Blumer (1970), el tratamiento de Mead de la sociedad humana mostraba que la vida en grupo "'s la condición esencial para el surgimiento de la conciencia, la mente, el mundo de los objetos, seres humanos como organismos en posesión de 'Selves' y de la conducta humana en Corma de actos construidos (constructed acts)" (p. 282). Actos construidos está subrayado porque, como se verá después, en la Terria del "Sell" de Mead la explicación de la conducta humana como un mero conjunto de respuestas fisiológicas que actuan reflexivamente hacia el ambiente está contrastada radicalmente con la concepción de los actos humanos como una actividad autodirigida $y$ construida de los individuos. La construcción de un acto humano incluye la identilicación de una lutura linea de acción, la observación e interpretación de las acciones de los demás, la evaluación de la situación individual, la craluación personal en diferentes momentos de la realización del acto, el establecimiento de una estrategia para saber qué hace en diferentes momentos y, frecuentemente, la estimulación a si mismo frente a disposiciones o situaciones desmotivantes. Sin embargo, dice Blumer (1970), "el hecho de que un acto humano sea auto-dirigido o construido no quiere decir en ningún sentido que el actor necesariamente exhibe excelencia en su construcción. De hecho, puede construir su acto de manera muy deficiente" (p. 284).

La Teoría del "Self" Social de Mead incluye: el "Scll", cl acto, la interacción social, de los objetos y la acción conjunta. Algunos autores (Dewey, 1931, Schellenberg, 1978) han destacado como una idea central en el pensamiento de Mead la continuidad que evolucionó como un principio metodológico en la construcción de su teoría social. Por esta razón, es dilícil separar su explicación del "Self" de su concepción del acto y su discusión de la interacción social, de los objetos y la acción conjunta. Teniendo presente lo anterior, presentamos en esta sccción el material solamente incluido en la obra póstuma de Mead Mind. Self and Society (1934) en su capitulo sobre el 
"Self"." El lector está advertido de que ésta es una presentación incompleta y contextualizada de la teoría de Mead.

Según Blumer, el individuo como actor era para Mead una creatura muy diferente a las concepciones contemporáneas en psicología y ciencias sociales. Esta concepción se caracteizaba por un organismo en posesión de un "Self". El impacto de la presencia del "Self" en el individuo lo impacta de tal manera que lo convierte en un tipo muy especial de actor, transformando su relación con el mundo y dando a su acción (actuación) un carácter único. Cuando Mead nos habla de un scr humano en posesión de un "Self", debemos entender que este ser es un objeto para sí mismo. Es decir, el individuo es capaz de auto-percibirse, tener una concepción de sí mismo y actuar reflexivamente, es decir, hacia sí mismo.

\section{El "Self" y el organismo"2}

Mead comienza por distinguir entre el organismo fisiológico como tal-y el "Sclf". El primero está alli cuando nacemos, el scgundo se desarrolla en el proceso de interacción del individuo con su ambiente. Dentro del ambiente que rodea al individuo, Mead destaca el conjunto de relaciones humanas. Es precisamente esta experiencia, evidenciada y dramatizada por la adquisición del lenguaje, que sirve de fundamento al "Sell".

En estas observaciones primeras de su teoria, Mead hace (lara su adherencia al punto de vista holista ${ }^{13}$ del desarrollo del "Scll" y a una concepción dinámica, vis-a-tis estática, del ser humano. Esto se hace evidente al notar su uso de los conceptos de desarrollo, proceso y relaciones. También e's importante destacar el espíritu dinámico que permea cl texto.

Al establecer la diferencia entre el organismo fisiológico y cl "Scll", Mead apunta -implícitamente- a una tesis de lo

"Casi toda la obra de Mead es póstuma. Colegas y estudiantes recolectaron su pcnsamicnto a partir de apuntes que él dictó en sus cursos. Los volumenes que contienen estas ideas han sido publicados por The University of Chicago Press.

12 La presentación de la teoría de Mead sigue la estructura de la acción de Charles W. Morris en 1934.

"3 Para un análisis histórico de la perspectiva holista en ciencias sociales ver: Phillips, D.C. 1976, Holistic Thought in Social Sciencie. 
que Phillips (1976) identifica como Holismo I: "el todo es más que la suma de sus partes" (p. 6). El siguiente análisis de Mead nos da más material para apoyar un cuerpo y un "Sell". Un cuerpo "está alli" y puede operar, incluso de manera inteligente, sin la presencia de un "Self". El "Self". (omo ya se apuntó antes, tiene la capacidad del individuo de objetivarse, es decir, de ser sujeto y objeto de conocimiento al mismo tiempo. Es perfectamente aceptable decir que el ojo ve al pic, sin embargo, no puede ver al cuerpo como un todo. Las experiencias corpóreas están organizadas alrededor de un "Scll". Las partes del cuerpo pueden distinguirse de este "Scll". Es más, podemos perder partes del cuerpo sin afectar scriamente al "Self". El cuerpo, entonces, no se experimenta a sí mismo como el "Self" lo experimenta.

\section{¿Cómo surge la conciencia de uno mismo?}

¿Cómo es posible que un individuo salga experiencialmente de tal modo que pueda ser objeto para sí mismo? Mead llama a cste proceso auto-indicación (Self indication) y lo refiere como un problema de naturaleza psicológica referida a la mismidad (Sclthood) o auto-conciencia. La auto-conciencia incluye un proceso racional, objetivo que se manifiesta en una actitud no afectiva hacia el individuo. También la situación social donde la persona está inmersa influye el proceso. En la medida en que el individuo puede reflexionar objetivamente, en esa medida se objetiviza. El contenido social de esta objetivización es la capacidad del individuo de verse a sí mismo desde los diferentes puntos de vista de los miembros de un grupo o desde un punto de vista generalizado del grupo al que pertenece. El individuo, pues, se convierte en "Self" en la medicla en que introyecta e incorpora las actividades que ouros tienc'n hacia él dentro de un ambiente o contexto social de experiencia o conductas donde todos (el individuo y los otros) cstán involucrados.

La caracteristica más importante de la explicación anterior es el reconocimiento de Mead de las habilidades reflexiras del individao, es decir, la capacidad del individuo de ser su propio objeto de conocimiento. Estas habilidades son po- 
sibles gracias a que se percibe como parte de un todo social: su grupo. Entonces, la auto-conciencia o la conciencia de sí mismo no puede surgir en aislamiento, no es concebible en un vacío social. La autoconciencia, pues, es posible tanto porque el individuo se experimenta como el destino de las refle. xiones de los otros hacia él como por la conciencia del individuo de que es parte de un todo social constituido por otros individuos que también son parte y todo.

La explicación de la auto-conciencia responde claramente a la cuarta tesis del Holismo 1 de Phillips (1976): "Las parues no pueden ser entendidas si son consideradas aisladamente (por: separado) del todo". En téminos de la explicación de Mead: la auto-conciencia (la parte) no puede ser concebida por separado, independientemente, del grupo (del todo). Más especificamente, la auto-conciencia no puede ser entendida aisladamente del grupo social: "es posible concebir el surgimiento de un "Self fuera de la experiencia social" (Mead, 1934 p. 204$)$.

\section{La auto-conciencia y la comunicación humema}

Según Mead la comunicación es una conducta que le permite al individuo ser un objeto para sí mismo. La commicación humana, pues, es una instancia de expresión del "Self": al tiempo que alecto a mi interlocutor con lo que digo, me afereto a mi mismo con lo dicho. Cuando un mensaje es un estimulo tanto para la persona que lo transmite a una segunda como para sí misma, se convierte (el mensaje) en un conjunto de simbolos significantes.

Mead nos dice que existe una diferencia entre la comunicación humana y otras formas animales de comunicación. Ilustra su punto estableciendo que no es lo mismo cl llamado de una gallina a sus polluelos o el aullido de un lobo a su manada y la comunicación de símbolos significantes. La comunicación humana involucra al "Self".

La comunicación humana, en tanto conversación con símbolos significantes, nos remite a lo que Mead refierc como el discurso o la argumentación significativa (significant specch). Esta consiste en una acción "que afecta al propio individuo y 
'ste efecto es parte del llevar a cabo inteligentemente la conversación con otros... Uno conversa con su 'Self' como uno conversaría con otra persona" (p. 205).

En esta instancia particular, Mead explica la comunicación humana como el resultado, la consecuencia de la capacidad del individuo de objetivarse. Esto es, reconoce que el individuo tiene habilidades reflexivas (v. gr., auto-conciencia) y, a través de símbolos significantes, se puede comunicar con los demás y afectarlos de la misma manera en que se afecta a sí mismo. La comunicación entre humanos está, pues, determinda por la capacidad reflexiva de las personas, por su auto-conciencia (Self-consciousness). Esta explicación está, en espiritu, cerca de la tercera tesis del Holismo I de Phillips: "El codo determina la naturaleza de las partes". Sin embargo, en seguida esto no es claro prima face como lo veremos en seguida.

Mead nos ha hablado de cómo un individuo sc transforma en persona al aparecer el "Sell". Esta persona desarrolla habilidades reflexivas al adquirir un lenguaje y experimentarse como parte de un todo social. Sin embargo, la persona surge también y paralelamente, como un todo social. Es precisamentc aquí donde la naturaleza de la comunicación humana es relevante, en tanto que la persona no sólo es un individuo sino una persona en posesión de un "Self" social, es decir, un individuo con auto-conciencia. La persona, como un todo, determina la naturaleza de su comunicación con los demás. Es el todo (la persona, el individuo con autoconciencia, el individuo con habilidades reflexivas) el que determina la naturaleza de sus partes (la comunicación con los demás): El individuo incorpora los procesos sociales generales y los organiza en su experiencia personal, lo cual constituye la base y prerrequisito para el máximo desarrollo del "Sell" individual. Queda claro que para Mead la sociedad es a la persona como la persona es a su conducta consciente (conductta con la presencia reflexiva del "Self"). Este paralelo "todopartes" es posible por la presencia del "otro generalizado" que Mead explica asi: "La comunidad organizada o grupo social que da al individuo su unidad de 'Self puede ser llamado 'el otro generalizado'. La actitud del otro generalizado es la 
actitud de toda la comunidad"' (p. 218). Esta es, sin duda, una de las instancias más elocuentes donde Mcad presenta su posición frente a lo que es la acción social y la formación de actitudes.

$$
E l \text { "yo" y el "mi" }
$$

Uno de los aspectos más conocidos y mejor logrados de la teoria del "Self" de Mead es su explicación del "yo" y del "mi". Ya habíamos mencionado que algunas explicaciones de Mead caen dentro de lo que algunos autores en ciencias sociales han llamado el pensamiento holista (v. gr., Phillips, 1976). También citamos la tesis holista acerca de la influencia del todo en sus partes. La descripción meadiana del "yo" y del "mi" ilustra claramente esta tesis. El "Self", es decir, la capacidad reflexiva de la persona es el todo que tiene dos partes: cl "yo" y el "mi".

El "yo" es la parte reactiva de la persona en las actitudes de los demás. Es, por decirlo de alguna manera, la parte originalísima que la persona aporta - a través de sus respuestascn su interacción con los otros. Estas actitudes que toma ante los demás son el elemento novedoso, la aportación de la persona. El "yo", afirma Mead, da un sentido de libertad, de iniciativa.

El "mi", por el otro lado, "representa una organización definida de la comunidd ahi en nuestras actitudes, la cual demanda una respuesta, pero la respuesta que tiene lugar es algo que sólo pasa. No hay seguridad en cuanto a clla" (Mead, 1934, p. 233).

La relación del "yo" y del "mi" es curiosa e interesante. Son cntidades que existen de manera independiente $y$, sin cmbargo, se pertenecen, están juntas. Son partes de un mismo lodo. Su separación, nos dice Mead, no es ficticia, es real. No son idénticos. El "yo" no es calculable, predecible. El "mi" demanda una respuesta del individuo de acuerdo con una situación, sin embargo, el "yo" que es la entidad que provec la respuesta nunca llega a dar la respuesta perfectamente adecuada a la situación. "El 'yo' tanto llama al 'mi' como responde a él. Tomados juntos constituyen una perso- 
nalidad tal y como aparece en la experiencia social. El 'Sell' es esencialmente un proceso social en marcha con dos fases distinguibles. Si no tuviese estas dos fases, no podría haber responsabilidad consciente y no habría nada novedoso en la experiencia" (Mead, 1934, p. 233).

En lo anterior encontramos en el trabajo de Mead una instancia teórica difícil de analizar. El problema de la dualidad en la unidad está presente cuando Mead discute las dos partes cstructurales del "Self": el "yo" y el "mi". El autor no se refiere explicitamente a ninguna estructura, sin embargo, cstablece un paralelo entre el "yo" y el "mi" y la estructura tripartita de la personalidad según Freud; el id o ello, el ego y al superego.

Por un lado, uno está tentado a tratar al "Self" como un tímino holista que, como antes dijimos, define su unidad en la clualidad. Aquí las partes (el "yo" y el "mi") están concebidas y explicadas como entidades interrelacionadas y dinámicas de un todo (el "Sell"). Están interrelacionadas porque se alectan mutuamente. Son interdependientes porque el "yo" es inconcebible sin el "mi" y el "mi" es contingente de la existencia del "yo" para su surgimiento.

Por otro lado, la concepción del "mi" es holista en el sentido de que no es solamente una mera internalización de normas sociales por parte del individuo sino de alguna manera se reliere al mismo contenido del otro generalizado, es de(ir, la completud del grupo social, una actitud a un todo social externo, organizado y unitario. El "mi" incorpora esta alteridad iotherness) al "Self".

La argumentación no puede ser positiva en cuanto a que el "yo" y cl "ini", como en el caso del otro generalizado, necesitan nuevos conceptos para definir partes de la estructura del "Self". A pesar de que la descripción estructural del "Sclf" de Mead está llena de colorido y utilidad, su explicación conlleva problemas de definición.

\section{Contraste de los "Selves" de James y Mead}

El objetivo de esta sección es sacar a la luz y analizar las formas distintas de entender y explicar el "Self" que estas dos fi- 
guras destacadas del pensamieiento norteamericano han ofrecido.

\section{Generalidades}

La primera y más obvia diferencia entre James y Mead es su aproximación particular al tema. Mientras James se ha preocupado por ofrecernos un extenso viaje por la naturaleza del "Scll", Mead ha preferido trabajar la dimensión vertical de la materia y nos da una profunda crónica de la fundación social del "Self".

Mientras James escribió su materia como psicólogo, Mcad lo hizo más como psicólogo social y sociólogo. James centra su atención en cómo el cuerpo, las normas sociales y el espiritu explican al "Self". El análisis de Mead nunca abandona cl ámbito comunitario, social.

James está interesado en describir cómo el "Sell". está alectado por los diferentes elementos de la experiencia de este mundo (v. gr., el cuerpo, el alma, las categorías trascendentales, etc.). Mead, por el otro lado, está más interesado en especificar cómo el "Self" surge del contacto con la realidad social y cómo este "Self" organiza esa realiả (v. gr., el otro generalizado), es decir, cómo conoce al orden social y lo afecta por medio de la originalidad, creatividad del "yo".

\section{Puntos especificos}

En esta parte del artículo ilustramos algunos puntos menciomados (n las generalidades y comparamos el trabajo de James y Mead a propósito del conceptó del "Self" social.

El "Self" social de James está caracterizado por la necesidad del individuo de ser notado por los demás, por una naturaleza polifacética e inclusiva y por un "club" de opiniones.

La descripción del autor enfatiza el mundo social externo del cual el individuo es parte. El tratamiento del concepto, mc parce, es unidireccional cuando habla del "Self" social. James está interesado en subrayar el hecho de que existe una división del individuo en varios "Selves". (Ver sección el "Self" social, arriba). Nuestro autor no está interesadó en ex- 
plorar cómo el individuo resuelve tensiones internas cuando alguno de sus "Selves" entra en conflicto. Ni siquiera quiere especificar cómo es que el individuo internaliza un conjunto de expectativas y roles que adquiere en la interacción social.

En su sección sobre el "Self' espiritual, James explica que dada nuestra naturaleza reflexiva y consciente podemos "pensarnos pensantes". Entre la teoría social del "club de opiniones" y la descripción intrasubjetiva, psicológica del flujo de pensamientos necesitamos un puente. Un puente que establezca la continuidad entre lo social y lo intrasubjetivo en James. No es una mera coincidencia que esta "brecha" sea cubierta por el trabajo de Mead. No es una coincidencia porque el propio Mead estaba muy atraído por la idea de continuidad, la cual manejaba en mucho como un evolucionista a la Darwin. La noción de continuidad ocupa un sitio central en su obra Mind, Self and Society (1934). algunas personas que conocieron a Mead, destacan la continuidad, incluso como característica personal, del autor John Dewey, citado por Schellenberg (1978), alguna vez sobre Mead: "su naturaleza original y lo que adquirió y aprendió, era una y la misma (cosa)... en su filosofía no existía división entre hacer, reflexionar y sentir porque no existía (tal división) en él" (Dewey, 1931). Schellenberg agrega: "Esta personaliad continua, especialmente la continuidad de pensamiento y acción, se daba aparentemente con mayor naturalidad en G. H. Mead que en la mayoría de los filósofos" (p. 55).

Volviendo una vez más al puente entre lo social y lo individual en James a través del trabajo de Mead, mencionamos de nuevo a Schellenberg quien nos ayuda a descubrir en la psicología social meadiana la continuidad entre individuo y sociedad, donde "Selves" individuales necesitan de una sociedad para surgir y ser creados de la materia (stuff) de la interacción social. También la sociedad -aunque evolucionada primero que las mentes autoconscientes- requiere en su forma humana de la participación de hombres y mujeres individuales" (p. 55):

Sin embargo, tenemos que reconocer que en el caso de Mead de la relación de continuidad entre el individuo y la sociedad, la última prioridad causal es para la sociedad. Esta 
posición es una de las razones por las cuales Mead ha sido tan influyente para los sociólogos, especialmente para los interaccionistas simbólicos.

Otro elemento que debe ser incorporado en este análisis es el concepto de "expectativas". Como se mencionó anteriormente, James hace una referencia indirecta a ellas cuando habla de fama, honor y el "club" de opiniones" pues destaca la presencia de grupos sociales influyendo en el individuo en sociedad. Mead, por otro lado, lleva la explicación de James un paso adelante. Toma a las "expectativas" como un principio organizador de la experiencia del "Self". Este trabajo de Mead ha dado dos vetas de estudio e investigación: por una parte, el área del auto-concepto (v. gr., ccuál es la imagen de una persona para sí misma?) y, por la otra, la teoría de los grupos de referencia (v. gr., ¿cuáles son los valores y normas que mis amigos, familiares, conocidos, colegas tienen y cómo ('spcran que yo actúe?).

Hasta ahora hemos mencionado dos elementos del puente mediano entre individuos y sociedad: continuidad y expectativas. Un tercer elemento es la capacidad del "Self" de objetivarse. Esta noción completa la explicación de Mead de la relación individuo-sociedad y establece un contraste interesante con el trabajo de James.

Cuando James habla de la naturaleza espiritual del "Scll" (ver la sección El "Self" espiritual), se refiere a la habilidad del individuo de incorporar su "Self" como parte del proceso de pensamiento. Es decir, las personas pueden pensarse como pensantes. Esta característica reflexiva de la conciencia es incorporada por Mead en su análisis del "Self" y contextualizada cuando este autor habla de la capacidad del ser humano de ser su propio objeto, lo que hemos llamado capacidad de objetivarse.

\section{Ultimos comentarios pragmatistas}

Cuando su viejo amigo, después cuñado, Henry Castle persuadió a Mead de acompañarlo a estudiar a Harvard y tener la oportuniad de conocer el trabajo de William James, Mead no se impresionó mucho de la psicología y filosofía de James. 
En aquel entonces sólo las clases de Royce impresionaron al joven estudiante de filosofia que pensaba que contenian "una textura de un libre fluir de ideas, abriendo la puerta a cuestiones más amplias sobre la naturaleza de la experiencia humana". (Schellenberg, 1978 p. 39). Sin embargo, muchos años después, al final de su carrera y de su vida, Mead se había establecido como una de las figuras centrales del movimiento pragmatista junto a sus maestros Royce y James, y a su amigo y colega Dewey. ${ }^{14}$

Como James, Mead tuvo mucha influencia del darwinismo. Como James, valoró la metodología científica y le dio un sitio preferencial en su pensamiento como contenido y principio organizador.

Según Mead, el surgimiento del pragmatismo se debió a la conjunción de dos desarrollos científicos: la psicología conductista y la metodología científica. La fundación conductual del pragmatismo viene de la teoría de la evolución biológica de Darwin. Fueron precisamente los Principles de James (1890) y el famoso artículo de Dewey (1896) sobre el arco reflejo los que atestiguaron y precipitaron el impacto del evolucionismo en psicología. Esta nueva aproximación a la psicología, eventualmente llamada "Funcionalismo", se transformó en una escuela de pensamiento establecida alrededor de la Universidad de Chiago donde Mead trabajó toda su vida. El trabajo de Mead llevó esta forma de estudio a la psicología social y, en consecuencia, "descubrió los méritos del conductismo, a pesar de que retuvo la concepción funcionalista de la evolución, carácter y utilidad de la mente. El funcionalismo continuó el ataque sobre el atomismo psicológico empezado por William James" (Reck, 1964, p. XVII).

Reck describe a Mead como uno de los historiadores más perceptivos de su generación que pudo captar el significado del pragmatismo en su contexto histórico y social, dos elementos (historia y sociedad) de la teoría de la verdad de James. En un trabajo publicado en 1903, Mead ataca -con Kant- a las teorías empíricas del "Self" como la de James

14 Ver "The Philosophies of Royce, James and Dewey in their American Setting" en Reck (1964), pp. 371-391. 
(Reck, p. i). En este artículo Mead comenta la pérdida de dignidad sufrida por el "yo" (entendido en términos de Mead como la parte original y creativa del "Self") en la psicología positivista de su tiempo. En cierta forma, pienso que esta crítica es la descripción de sus aspectos empíricos pero se debe reconocer que James incorpora en su análisis los aspectos conscientes, mentales del "Self". Mead está èn lo correcto al situar a James en la tradición empiricista ${ }^{15}$ pero no creo que James se sintiera a gusto de ser puesto junto con los positivistas.

Una década después, Mead expuso en su "The Social Sell" (1913) una mejor, más clara y precisa manera de entender su oposición a las teorías del "Self" como la de James. El "Scll", decía, no puede aparecer en conciencia como un "yo". El "mi", por otro lado, es inconcebible sin un yo, un sujeto del cual puede ser un objeto (ver Reck; 1964, p. xxxi). En suma, lo que a Mead no gustaba de la teoría de James era su tono individualista, ignorando lo que lo social tiene de fundamental (foundational). dical".

15 Incluso el propio James nombró sú pensamiento maduro "Empirismo Ra- 


\section{REFERENCIAS}

ABBAGNANO, N. (1963)/ Dicciconario de Filosofía, México: Fondo de Cultura Económica.

BLUMER, H. (1937): "Social Psychology", pp. 148-198 en E.P. Schmidt (ed), Man and Society, New York, Prentice-Hall.

BLUMER, H. (1970): "Sociological implications of the thought of. G.H. Mead" en G.P. Stone and H.A. Farberman: Social psycho$\log y$ through symbolic interaction, Waltham, Mass.: Xerox College Publishing.

COOLEY, C.H. (1902): Human Nature and the Social Order, New York: Charles Scribner's Sons.

DEUTSCH, M. y R.M. KRAUSS (1976): Teorias en Psicologia Social, Buenos Aires: Paidós.

DEWEY, J.|(1896): "The Reflex Arc Concept in Psychology", Psychological Review 3 (July): 357-370.

DEWEY, J. (1922): Human Nature and Conduct, New York: Henry Holt.

DEWEY, J. (1931): "George Herbert Mead", The Journal of Philosophy, 28: pp. 309-314.

JAMES, W. (1890): Principles of Psychology, 2 vols. New York: Henry Holt.

MEAD, G.H. (1903): "The Definition of the Psychical", en The Decennial Publications of the University of Chicago. "First Series". Volume 3. Chicago University Press. pp. 77-112.

MEAD, G.H. (1913) "The Social Self', The Journal of Philosophy, PsYchology and Scientific Methods, 10:374-380.

MEAD, G.H. (1934); Mind, Self and Society: from a standpoint of a Social Behaviorist, Charles W. Morris (ed). Chicago: University of Chicago Press.

MELTZER, PETRAS Y REYNOLDS (1975); Symbolic Interactionism

NEWCOMB, T.M. (1950): Social Psychology, New York: The Dryden Press.

PHILLIPS, D.C. (1976): Holistic Thought in Social Science, Stanford: Stanford University Press.

RECK, A.J. (ed) (1964): Selected Wiritings: George Herbert Mead, Chicago: University of Chicago Press.

SCHELLENBERG, J.A. (1978): Masters of Social Psychology, New York: Oxford University Press. 